\title{
A Little-Known Chapter in the History of Computing in Belgium: The Machine Mathématique IRSIA-FNRS
}

\author{
Marie d'Udekem-Gevers \\ Faculty of Computer Sciences, University of Namur, Belgium \\ marie.geversaunamur. be
}

\begin{abstract}
Based on original documents, this article deals with the first stored program computer designed and built in Belgium in the early 1950's, the $M a$ chine Mathématique IRSIA-FNRS (MMIF). After addressing the history of this prototype, it describes the Machine and highlights its specificities. Then, showing how the computing techniques that led to this machine were originally disseminated in Belgium, it underlines the Swiss (particularly Eidgenössische Technische Hochschule (ETH)) influence on this project.
\end{abstract}

Keywords: Belgium, dissemination of innovations, history of computing, stored program computer.

\section{Introduction}

The present contribution ${ }^{1}$ addresses a subject that remains largely ${ }^{2}$ unknown: the origins of computing in Belgium. It discusses the design and building in Antwerp of a computer known at the time as the Machine Mathématique IRSIA-FNRS ${ }^{3}$ (MMIF) because it was funded by the Institut pour l'Encouragement de la Recherche Scientifique dans l'Industrie et l'Agriculture (IRSIA) and the Fonds National de la Recherche Scientifique 5 (FNRS).

The information presented here is the result of research ${ }^{6}$ begun in 2005 and completed in 2011. The study focused initially on interviews with pioneers in the computing field ${ }^{7}$. Each of these interviews was conducted in a semi-directed manner and was audio-taped ${ }^{8}$. Each taping was then transcribed and sent to the interviewee for corrections. However, it quickly became apparent that, in order to confirm details or resolve any ambiguities or contradictions, it would be necessary to telephone the interviewees

It is a summary of a detailed monograph [33], published only in French.

2 When the monograph summarised here was being printed, P.-J. Courtois published an account about this same machine [32].

3 See Figure 4. The IRSIA-FNRS Mathematical Machine.

4 Institute for the Promotion of Scientific Research in Industry and Agriculture.

5 Belgian National Fund for Scientific Research.

6 Sandra Mols collaborated in this research from 2007 to 2009.

7 This was how Jean Meinguet, Nicolas Rouche, Claude Fosséprez and then later André Fischer were interviewed.

8 Each tape recording has been added to the "Histoire informatique belge" Archival Fund (HIBAF). 
after the interviews or to contact new eyewitnesses. Furthermore, during the study, Email exchanges became increasingly important and relevant. They enabled us to compare diverging accounts and also to encourage reminiscences. In all, twelve people ${ }^{9}$ who were actively involved in the history of the MMIF were contacted and gave their accounts. In addition, these eyewitnesses provided contemporary documents ${ }^{10}$ about the Machine: texts pertaining to the description, functioning and programming of the MMIF, as well as photos from that time. On the basis of these eyewitness accounts and, above all, the contemporary texts and photos about the MMIF, I began to write a technical description of the Machine. Then, I systematically gave the eyewitnesses the texts I had written for corrections and additions. Subsequently, it became evident to me that the historical context of the prototype would have to be addressed. There were major gaps in my information about this subject, and therefore I went to the FNRS Archives. Using photocopies of documents found there, I was able, step by step, to write the detailed history of the MMIF. This text was further enhanced with information from other sources already gathered about the Machine. Finally, the completed monograph was sent to a number of people (including participants in the MMIF project), who agreed to read it and make any suggestions for improvements.

\section{Historical Context}

The first event that would lead to the building of the MMIF dates back to 3 May 1946 [25]: this was the decision by the FNRS Board of Directors to ask Professor Charles Manneback ${ }^{11}$ (Université Catholique de Louvain) and $\mathrm{Mr} \mathrm{L}$. Brillouin (Collège de France) to conduct a survey of "large mathematical machines" in the USA. This mission would lead to a report submitted to the FNRS on 16 June 1947 [27]. During the winter and spring of 1947/48, M. Linsman (an assistant at the Université de Liège) and $\mathrm{W}$. Pouliart (an engineer for Bell Telephone Manufacturing Company (BTMC) in Antwerp) participated in building and setting up the Mark III machine at Harvard University under the direction of Professor H. Aiken. On 15 June 1949, Willems (FNRS Administrator-Director), Linsman, Pouliart and Henry (IRSIA Director) met in order to agree on a future course: Linsman and Pouliart would write a machine construction project in a few months and BTMC would provide the facilities necessary for completing this project. In August 1950, Professors Aiken, Manneback and Boulanger (Professor at the Université Libre de Bruxelles and the Faculté Polytechnique de Mons) met at Harvard to discuss the project written by Linsman and Pouliart. That same year, IRSIA and FNRS agreed to finance the execution of the project, via the "Comité pour l'étude et la construction de machines à calculer électroniques" "12 (CCCE), which was specially created for this purpose. On 16

\footnotetext{
9 The ten main eyewitnesses were the four people cited above as well as Paul Dagnelie, Armand de Callataÿ, Frédéric Iselin, Jacques Loeckx, Paul Parré and Fritz Wiedmer. Pierre Macq and Guillaume Van Mechelen also provided some information.

${ }^{10}$ These documents (either originals or copies) have also been added to HIBAF.

${ }^{11}$ See [30].

${ }^{12}$ Committee for the Study and Construction of Electronic Calculating Machines.
} 
and 17 January 1951, Professors Aiken, Manneback and Boulanger, Mr. Pouliart and Mr. Linsman met at the IRSIA and compiled 16 recommendations (including the 'specifications' for the MMIF) [23]. A few days later, an agreement [26] was signed, containing the following clauses:

"It is hereby agreed [...]

e/ that the Committee and Bell Telephone shall undertake all necessary measures to ensure that a certain number of scientists - engineers, mathematicians and physicists - are assigned to design and build the Machine and are trained in the techniques for the building and use of said Machine;

$\mathrm{f} /$ that the building shall be performed under the leadership of $\mathrm{Mr} \mathrm{W}$. Pouliart, Mr. Linsman and Mr. Belevitch ${ }^{13}$ working on it full time."

In early May 1951, the design of the MMIF began, followed almost immediately by work on its construction. On 14 May 1952, following a visit to BTMC, Aiken wrote a letter [21] in which he recommended a few new improvements and proposed a schedule for completion. In June of that year, the assembly ${ }^{14}$ of the MMIF commenced.

On 13 December 1954 [24] the initial version of the MMIF (17 racks), located on the top floor of an old BTMC building became operational. In January 1955, King Baudouin of Belgium was given a private tour, and then the Machine was officially unveiled on 12 February of that same year ${ }^{15}$.

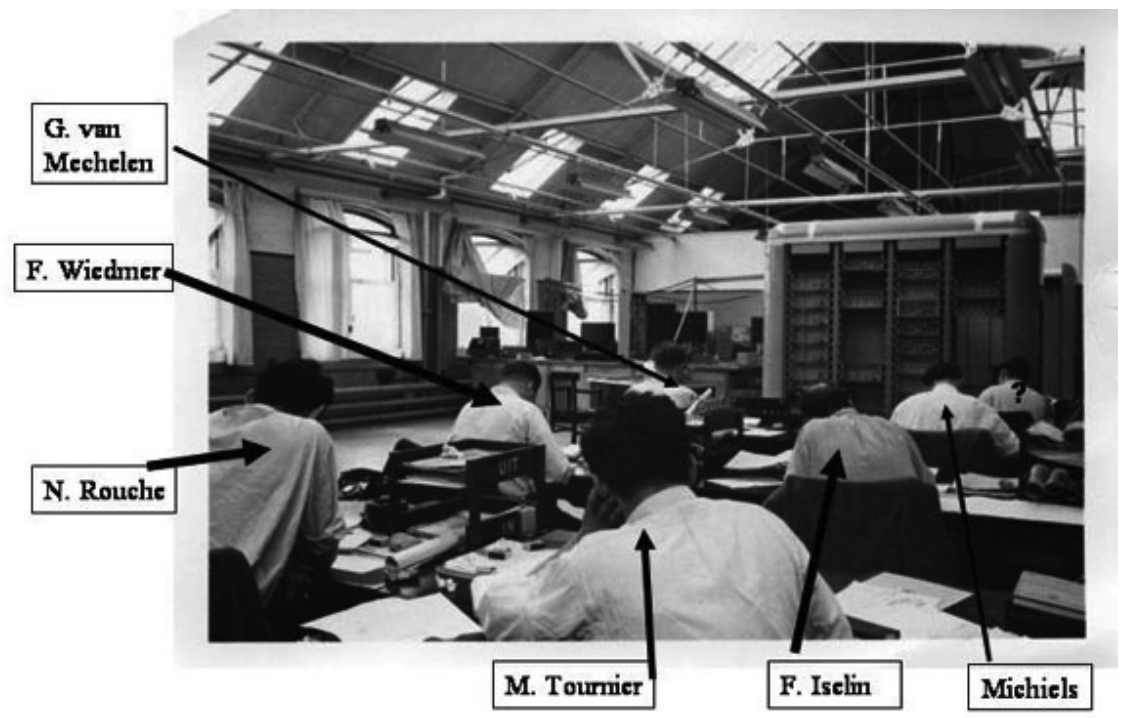

Fig. 1. People responsible for designing the MMIF, in front of the machine during construction (Source: HIBAF with annotations by M. d'Udekem-Gevers)

\footnotetext{
${ }^{13}$ See [31].

${ }^{14}$ See Figure 1.

15 See Figures 2 and 3.
} 


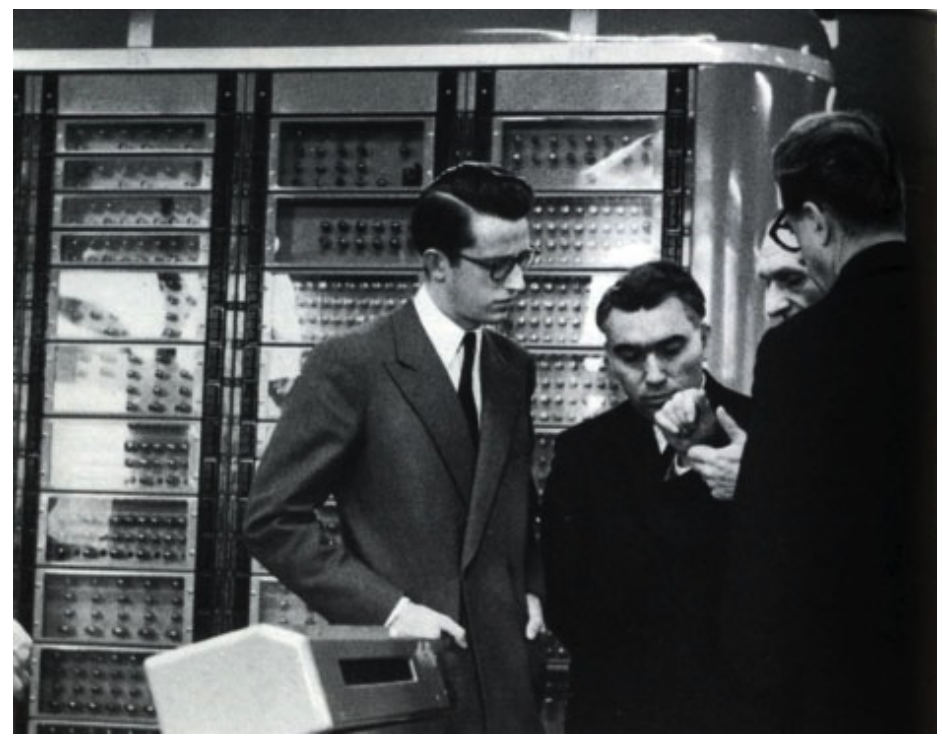

Fig. 2. Private tour for the King of Belgium (Source: [18])

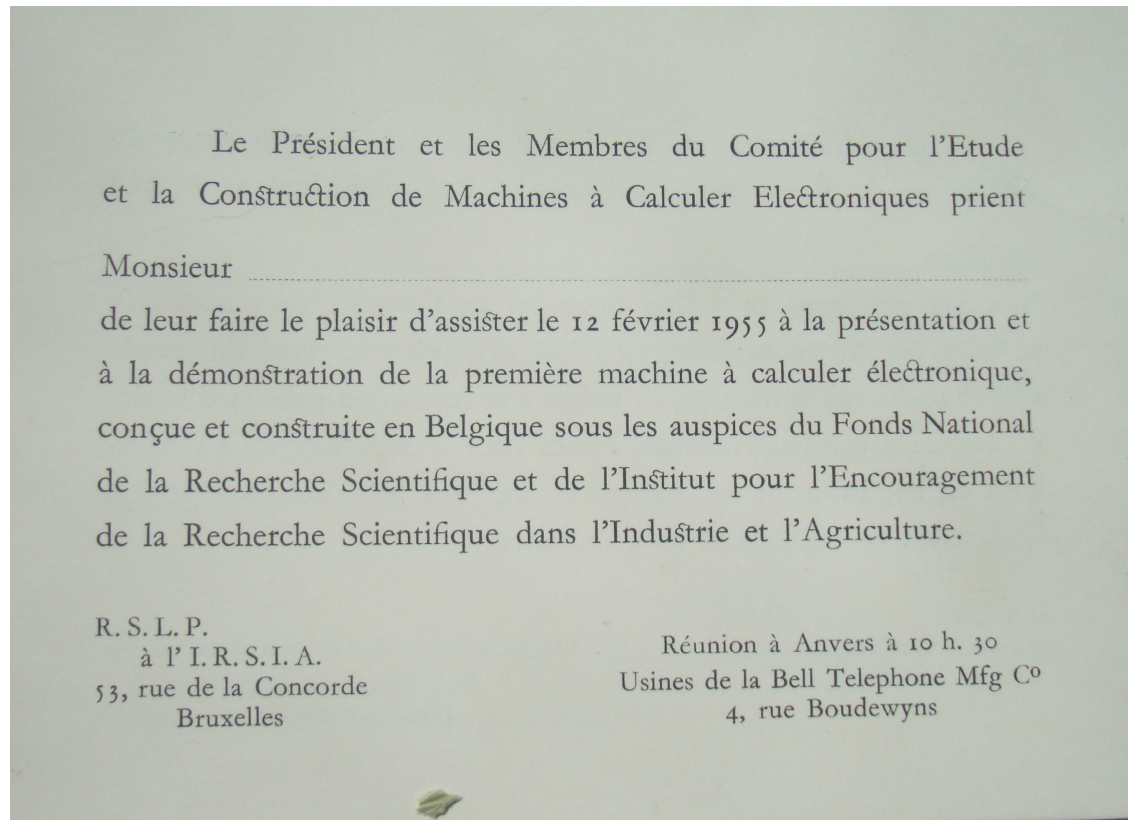

Fig. 3. Invitation to the unveiling ceremony of the Machine (Source: FNRS Archival Fund)

The day after the unveiling, the commissioning and practical use of the MMIF began. In March 1955, the "Comité d'étude et d'exploitation des calculateurs électroniques" $"$ (CECE) was created, with Belevitch named as chairman soon thereafter.

${ }^{16}$ Committee for the Study and Use of Electronic Calculators. 
In late December 1956, the final version of the MMIF (34 racks) was completed, and it was moved to a new location in the new BTMC tower. Soon thereafter, a testing and correction phase started and was completed in late March 1957.

The operational period came immediately after this test phase. On 10 July 1957, a favourable assessment about the MMIF was written by Aiken and van Wijngaarden ${ }^{17}$ [22]. Both were later present when the MMIF was received by the CCCE. From midMay to early November 1958, use of the MMIF was temporarily interrupted when the Machine was being moved from Antwerp to Brussels. Then operation continued until April 1960, when use of the MMIF was discontinued on an almost definitive basis. However, it was only in late December 1962 that the CECE was effectively disbanded.

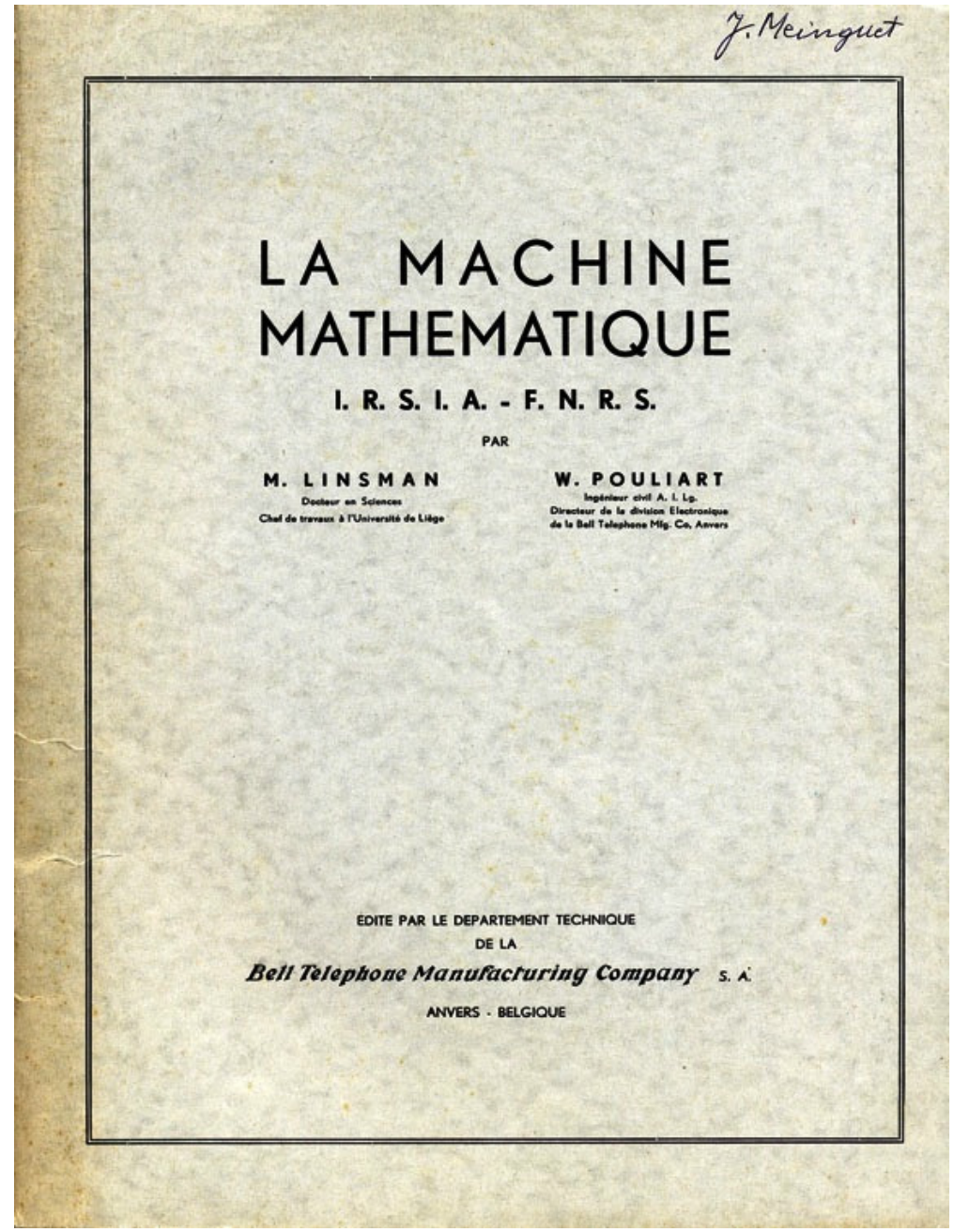

Fig. 4. Cover photo from [19] (Source: HIBAF)

${ }^{17}$ A. van Wijngaarden was the head of the Computing Department at Mathematisch Centrum in Amsterdam. 
The real overall cost of the MMIF has been able to be calculated on the basis of several documents contained in the FNRS Archival Fund. It amounted to 25,515,000 Belgian francs at the time ${ }^{18}$. This was almost four times the cost as it was first foreseen in 1950. Of this total, 22,935,000 francs were provided by IRSIA and the FNRS while the remainder came from Bell.

\section{Anatomy of the Machine}

\subsection{Designation and Definition}

The MMIF was considered at the time to be a "universal scientific digital computer" [15]. In current terminology, it is known as a stored program computer.

\subsection{Logical Architecture}

The logical architecture of the MMIF is classical: it can be described as being composed mainly of five parts or "components" [19]:

1. Memory: on which the data and programs are written separately. This distinction between the two types of memory is characteristic of what is now called "Harvard"19 architecture;

2. "Arithmetic unit" [15]: which is in charge of basic arithmetic operations;

3. "(Automatic) Control" [19], also known as the "control circuit" [29]: which distributes "instructions provided by the program to the Machine" [29] ;

4. "Input components" [29];

5. "Output components" [29].

\subsection{External Aspects}

The following is the description of the "initial" MMIF in 1955, provided by Linsman and Pouliart [19]: "The Machine is in the form of a set of racks arranged around the perimeter of an open rectangle ${ }^{20}$ behind and inside of which the magnetic memory cylinder is housed. Its footprint is $7.50 \mathrm{~m} \mathrm{X} 2.50 \mathrm{~m} \mathrm{X} 2.50 \mathrm{~m}$ ”. These authors [19] also state:

"The [standard] racks, which are $20 \mathrm{~cm}$ deep, are similar to those used in Bell Telephone Manufacturing $\mathrm{C}^{\mathrm{o}}$ transmission equipment [...]. All the parts in the racks are removable, and spare parts are available for a quick return to service in case of a breakdown."

\footnotetext{
18 This investment added up to 178 millions Belgian francs at the end of 2010 (considering inflation since 1955 according to IMF), that is to say 4.4 millions euros.

${ }^{19}$ Wikipedia. This architecture should therefore be distinguished from von Neumann's, in which this separation does not exist.

20 This is clearly illustrated in Figures 5 and 6.
} 
The "final" MMIF had 34 racks and as a function of its successive locations, it had first an L-shape (13 $\mathrm{m}$ long) and later regained a U-shape.

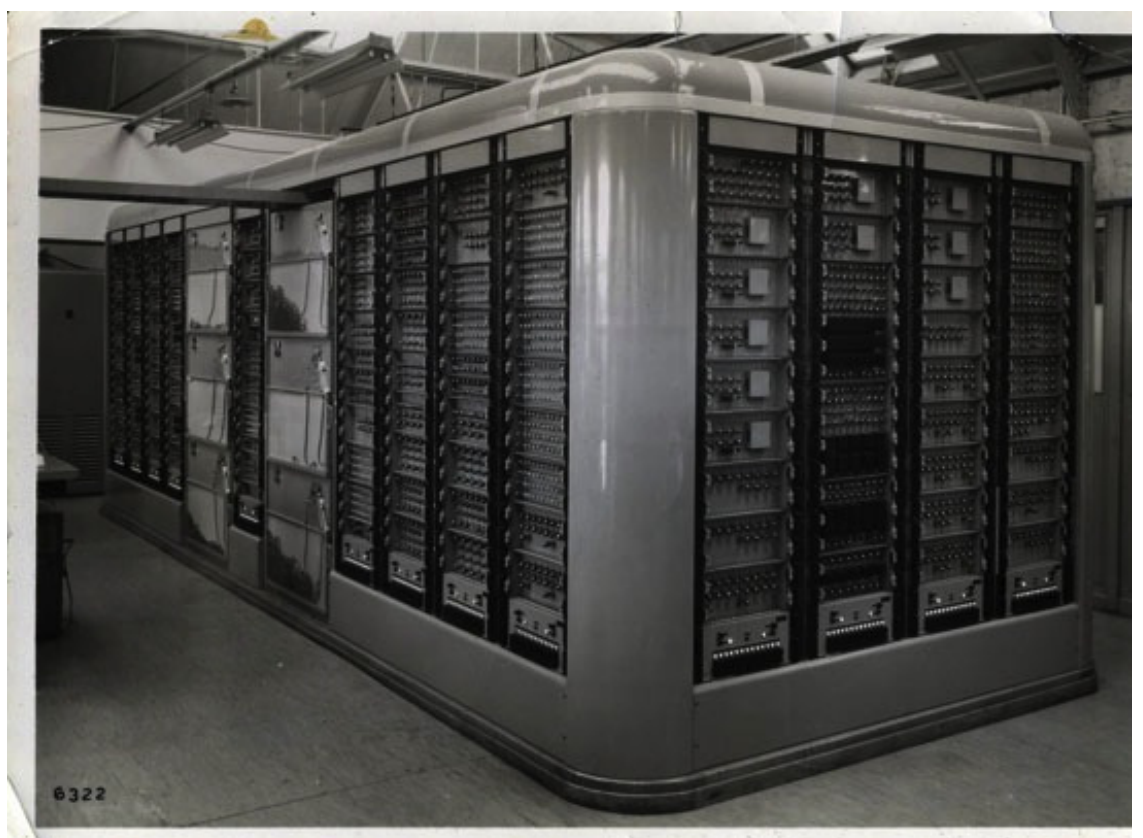

Fig. 5. The "initial” MMIF (with 17 racks), front view (Source: [19], photo I)

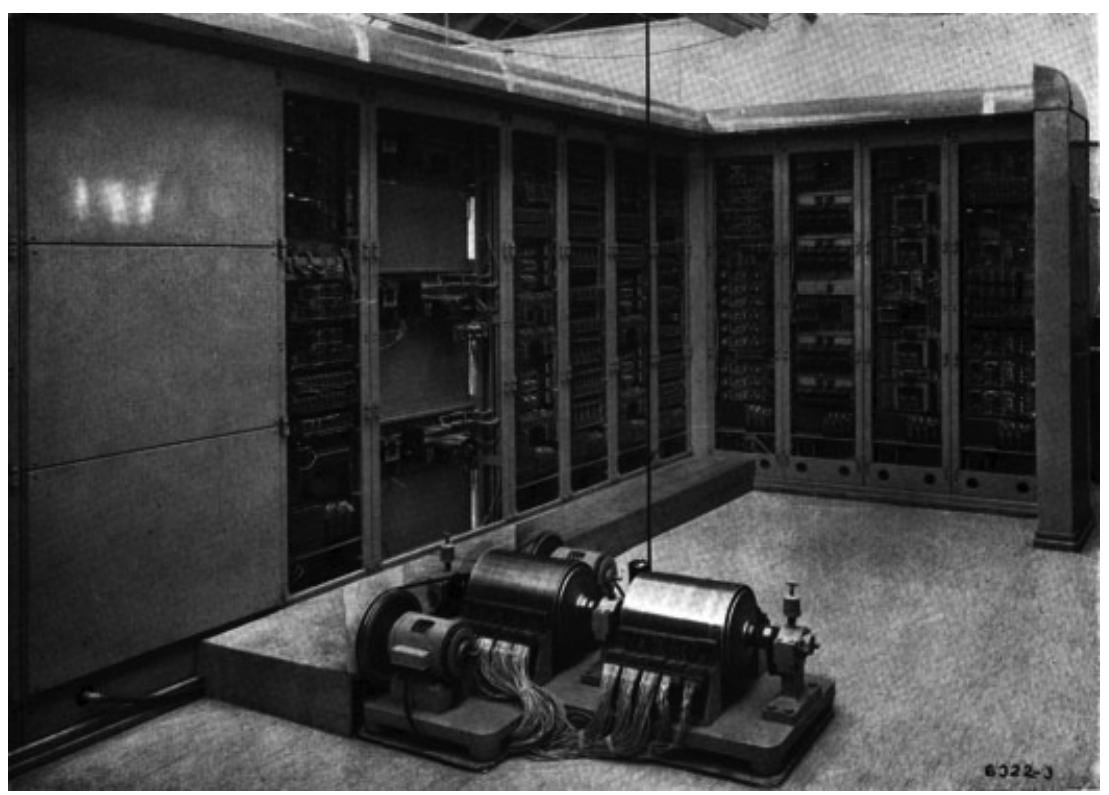

Fig. 6. The "initial" MMIF, rear view (Source: [19], photo II) 


\subsection{Description of the Physical Architecture}

\section{Introduction}

In 1955, according to Linsman and Pouliart [19]: "the Machine had about 3,000 hot cathode vacuum tubes, 1,000 cold cathode gas tubes, 400 relays, 1,000 selenium rectifier diodes and about 5,000 germanium diodes. It used about $15 \mathrm{~kW}$ of power." In 1957, according to the CECE, these numbers were the same for the rectifiers and gas tubes, but the MMIF then had 5,000 hot cathode vacuum tubes ${ }^{21}$ and used $25 \mathrm{~kW}$ of power [15].

We should state that the MMIF was, according to Meinguet [8], analogous to the Harvard Mark IV machine. While the MMIF did use technology from across the Atlantic, it is nevertheless true that it was also the opportunity, on the local level, for innovative technical research and execution in computer hardware. Linsman and Pouliart [19] note that there were certain components "whose design clearly differentiates MMIF from other computers." These authors [19] list the following distinguishing features:

- $\quad$ The magnetic tape memory;

- The magnetic cylinder memory;

- Amplifiers to record and read magnetic signals;

- Electronic memory on cold cathode gas tubes;

- The arithmetic unit.

Owing to a lack of space, we will focus here only on the memory units ${ }^{22}$ and in particular on those that make the MMIF unique.

\section{Physical Memory}

We can classify, in line with Rouche [5] and Loeckx [35], the memory of the MMIF in three categories as a function of access time: slow memory, faster memory and fastest memory.

Until (at least) 1957, the only slow memory cited in the texts used magnetic tape technology. This involved six identical mechanisms "23 "which can be used either to provide input for the Machine or to collect calculation results. They are composed each of a small pulley and a pneumatic device whose combined action controls the movement of a continuous magnetic strip" [29]. "On the tape, the whole made of the word and its address forms a series of 22 figures, with the address before the word [...]. A tape is able to hold more than 2,000 words. [...] The reading or writing time on the tape is about $30 \mathrm{msec}$. per word, the starting and pausing time after each word being included." [14]

${ }^{21} \mathrm{~F}$. Wiedmer [12] states: "The increase in racks to 34 and vacuum tubes to 5,000 was mostly due to the more elaborate control and program circuits".

${ }^{22}$ A description in English of the arithmetic unit can be found in [32].

${ }^{23}$ See Figure 7. 


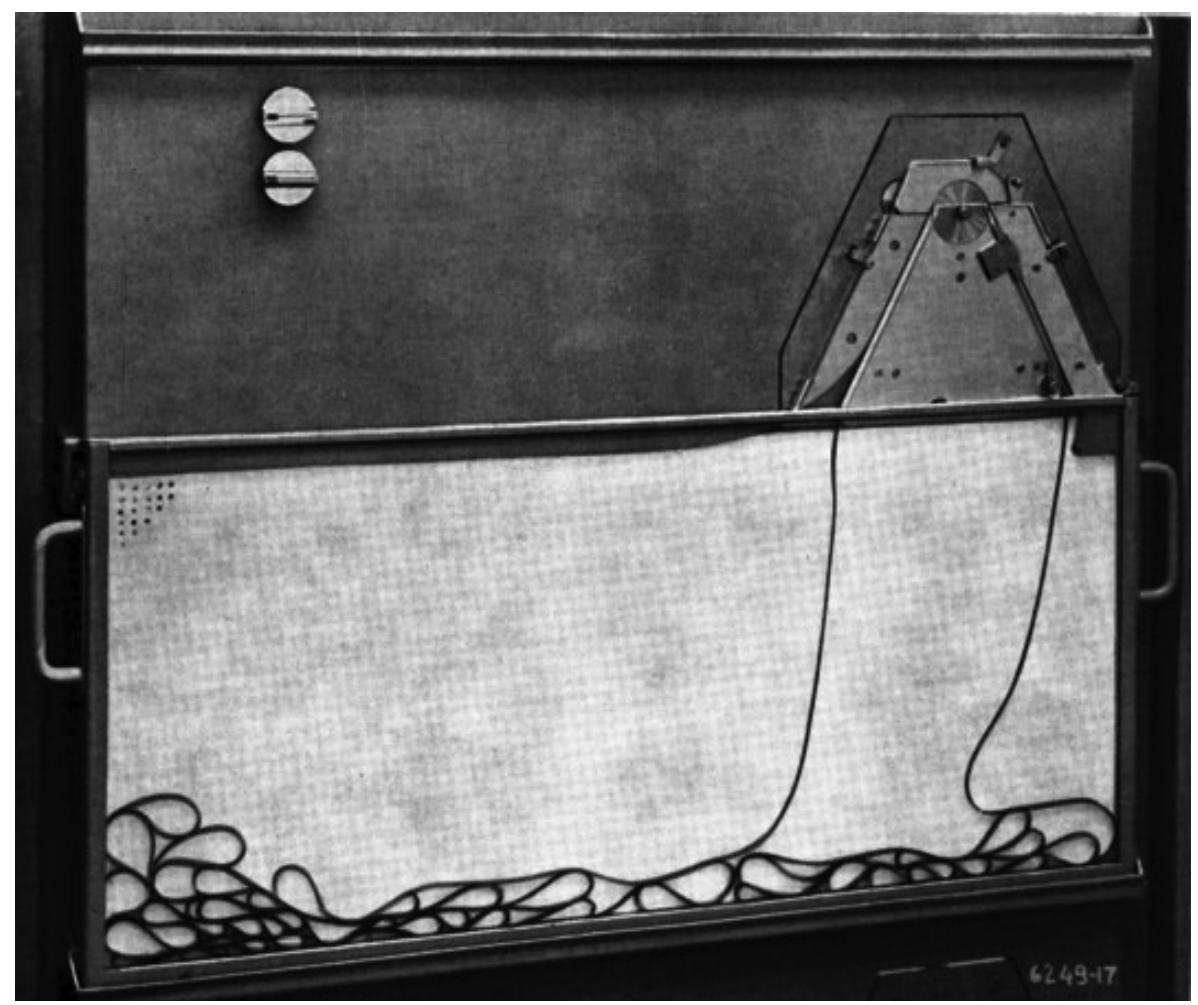

Fig. 7. One of the six magnetic-tape memories (Source: [19], photo III)

The MMIF also had a magnetic cylinder memory ${ }^{24}$, which was faster, and built entirely by BTMC [19]. As Figure 8 shows, this cylinder was actually composed of two half-cylinders, each made of five discs stacked on a single axis. In the photo, one can also see the "writing and reading heads placed above and below a brake shoe-shaped support along the two axes of the cylinders" [34]. The double cylinder "has 200 circular tracks or channels: one hundred of them are reserved for numbers and the other hundred for programs" [29]. The capacity of the cylinders is "2,000 decimal numbers (a 15-digit mantissa and a two-digit exponent with their signs) and 4,000 instructions," according to Fosséprez [34], who was one of the instrumental actors in implementing this magnetic memory. "In the drums, the information is divided into 18-digit words (numbers or pairs of instructions) whose location is given by a fourdigit address" [14]. We can also cite some numerical values: the rotational velocity of the cylinder is 4,100 rpm, and the average access time (individual selection of a word) is $7 \mathrm{msec}$ [15].

${ }^{24}$ It corresponds the component referred to above as "memory". 


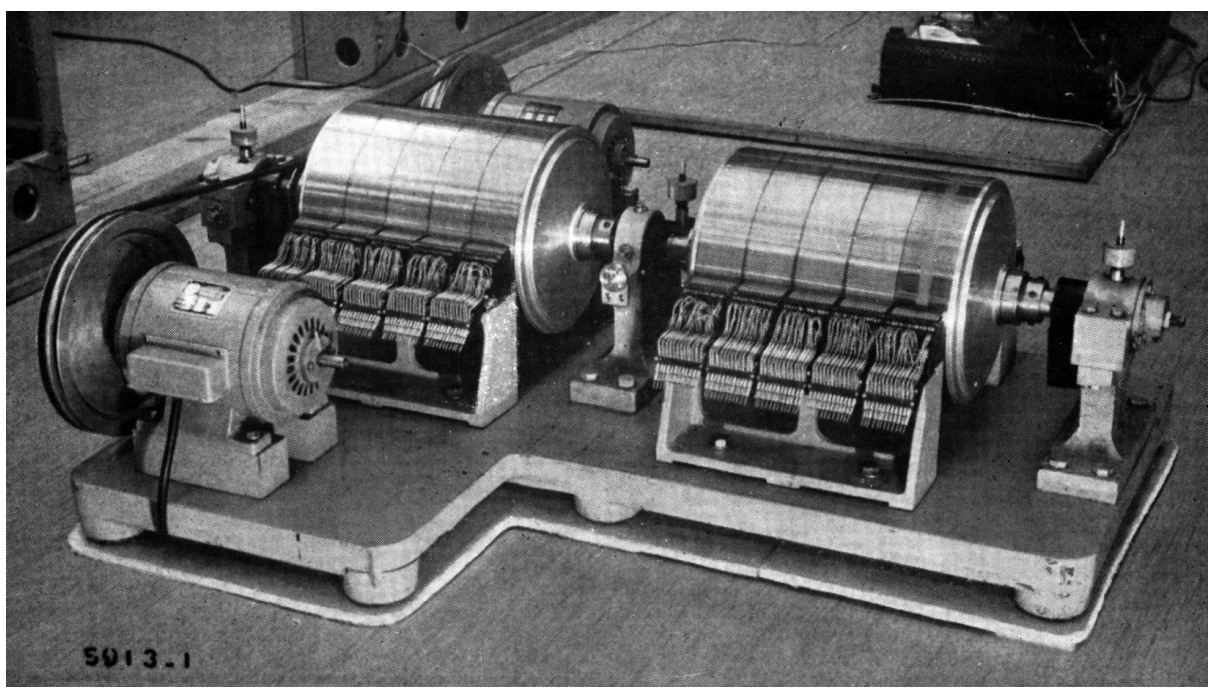

Fig. 8. Magnetic memory cylinder (Source: [19], photo IV)

The very fast memory of the MMIF is obviously electronic. "Two types of electronic memory" were used: the first involved "[cold cathode] gas tubes" [19] and the second hot tubes.

The cold cathode gas tube technology is specific to the Machine: it was the Bell Company that had the idea to use an existing, commercially available neon tube to make memory. "The tubes are assembled in rows ${ }^{25}$ in which a direction of flow is established, such that when an advancement pulse command is given, each tube sends its information to the next tube," explain Linsman and Pouliart [19]. "A row of memory of this type ran, under laboratory conditions, at the frequency of 70 kilocycles per second, which is the speed limit of the tube... This type of row is used, in this machine, at frequencies between 0 and 25 kilocycles per second. " [19] "In general, the use of memory rows on cold cathode gas tubes enables significant desynchronisation of the Machine" [19]. As such, the gas tubes were used in particular for asynchronous transfers between drums and magnetic strips and between the cylinder and the arithmetic unit [29]. These rows of memory also played a fundamental role in constituting the arithmetic unit [19].

Hot tube technology was used to make the fastest memory employed by the MMIF [1]. It was used in many places: in particular, to make the logic gates which played a role in implementation of the control unit. It also participated in the making of the arithmetic unit [19]. However, this form of memory can be "found in any electronic machine" [29].

${ }^{25}$ See Figure 9. 


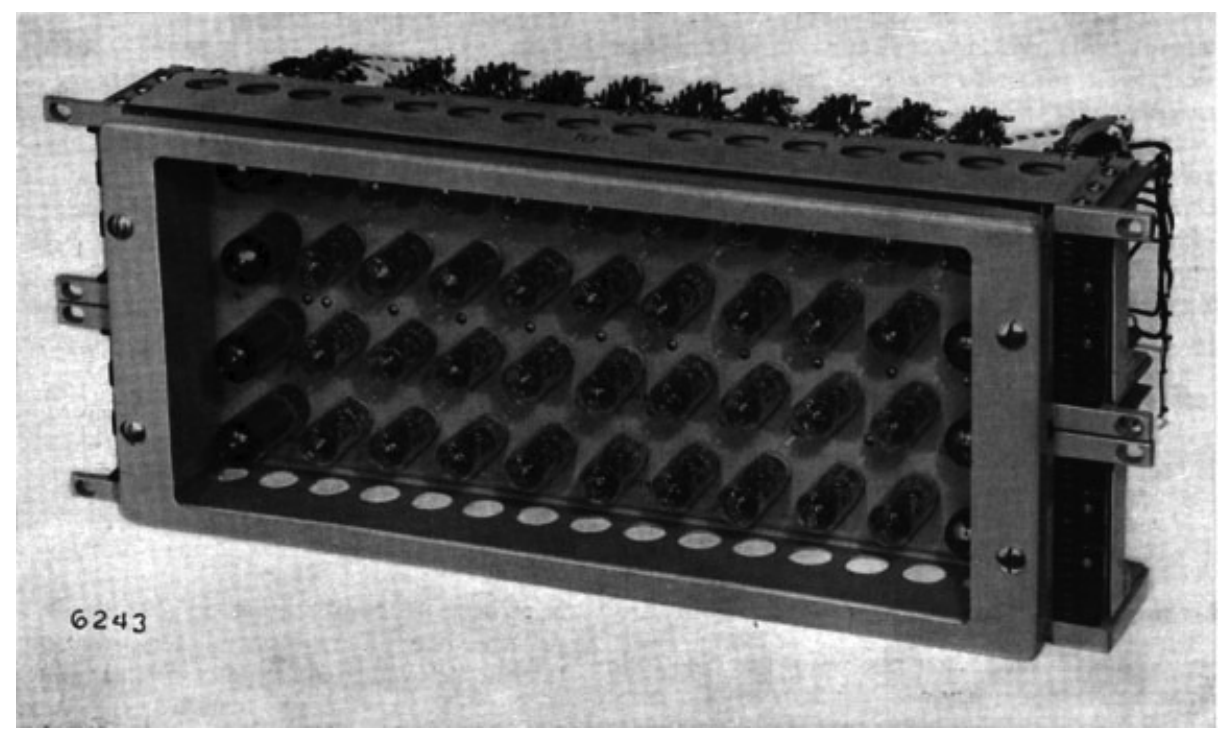

Fig. 9. Front view of a rack frame containing, in the centre, nine columns of four cold cathode gas tubes ${ }^{26}$ (Source: [19], photo VII)

\subsection{Programming}

The pioneers who built the MMIF were confronted with a twofold challenge: the first was to design a code (or language) that could be used to program the machine and the second was to write programs.

\section{Programming Codes}

"The Machine has a single address, which means that any instruction (or order) is composed of an operating prefix followed by a single address"[14]. "The address contained in an instruction may be the address for a number (operation instruction or write instruction) or the address for a pair of instructions ('renvoi' instruction)" [14]. In fact, two programming codes were written for the MMIF: the first is known as the "[regular] code" and the second, simpler one, is called the "pseudocode".

The (regular) code used for programming the MMIF was obviously the work of specialists in electrical circuits or hardware in general [4]. Using the original vocabulary, we can make up the following $\operatorname{list}^{27}$ of its main orders:

1. "operation orders" (in particular, addition, subtraction, multiplication);

2. "write orders" on the drum or tape or register;

3. "alterations" (operations "affecting a single number, and modifying its different parts or making permutations between them (sign, mantissa, exponent)";

${ }^{26}$ Four gas tubes correspond to a decimal number represented in bi-quinary code. Nine columns of four tubes correspond to an instruction or a half-number [34].

27 This list has been compiled from selected information in [14] and [15]. 
4. "usual organisation orders" for the drums (since "the left and right drums can each be used to record numbers or pairs of instructions) and tapes;

5. "calls, whether conditional or not";

6. "operations on addresses";

7. "transfer organisation", i.e. the movement of data or instructions, e.g. from the tape to the drum or vice versa.

This (regular) code was found to be difficult to use. An improvement was therefore sought out, leading to the pseudocode. According to Meinguet, who was the linchpin in programming the MMIF from 1956 onwards, the pseudocode was practically on the level of an assembly language, since it was a simplification of the machine language ([regular] code), particularly by replacing a five-digit prefix with a two-digit prefix and, above all, by replacing some addresses with designators.

\section{Programs}

Let us first look at the programs known at the time as "routines". They were written using [regular] code. Some were used by each program [14]. The routines were as follows:

- "start-up program" (written permanently on the instruction drum);

- "initial transfer program [from the tape to the drum]", written on tape;

- printing program;

- "translation routine" (called up by all programs in pseudocode) [16].

Other routines were called up by certain programs only. These include the routines that calculated elementary functions ${ }^{28}$ (inverse, $\sin \mathrm{x}, \log \mathrm{x}$, etc.). According to the CECE [14], these sequences were built solely "using calculation methods described in the article by V. Belevitch and F. Storrer"29. These methods were aimed at the "approximation of functions by polynomials, with a defined maximum relative error" [28]. Some of them are original in conception. As such, we can see that the building of the MMIF was also coupled with research in numerical analysis.

The other programs, i.e. the "programs for customer problems", were first written in "code" and then, as soon as possible in "pseudocode" [3]. This occurred starting in 1955, with experimental programs (particularly for the calculation of Bessel functions as requested by the École royale militaire ${ }^{30}$ ). However, in late March 1957, a regular programming period began for a variety of customers [17], in particular: the Institut météorologique $^{31}$, the Fabrique Nationale $(F N)$ d'armes de guerre ${ }^{32}$, the Université de Liège and the Commission des tuyauteries ${ }^{33}$.

\footnotetext{
${ }^{28}$ See [32].

${ }^{29}$ See [28].

${ }^{30}$ Royal Military Academy of Belgium.

${ }^{31}$ Belgian Weather Institute.

${ }^{32}$ National Weapons Plant.

33 Pipes Commission.
} 


\section{Discussion}

Several documents from the 1950's describe the US influence on the MMIF. For example, the preface to the 1955 text by Linsman and Pouliart [19] highlights the role played by Howard Aiken. However, several documents from that time ${ }^{34}$ also stress that the design and building of the MMIF were Belgian. And these Belgian achievements were made at the suggestion of Aiken himself [20]. As Henry [25] stated during the unveiling of the MMIF in 1955: "We could have purchased a machine, we could have copied a machine that had already been tried and tested, but more than anything we wanted to spark interest in new automation techniques and, by undertaking a difficult, long-term project, we wanted to orient young people towards promising new pathways."

To try to understand Aiken's contribution to the Belgian project in greater detail as well as the manner in which computing technologies were spread to Belgium, I interviewed the eyewitnesses in great depth. As far as MMIF architecture is concerned, the accounts by Wiedmer and Iselin, two Swiss engineers who designed the circuits of the Machine, have proved capital in this respect. "Using two drums, one for data and one for programs, was decided by W. Pouliart who had visited Harvard," Wiedmer readily admitted [11]. However, he immediately added: "I do not remember anything else that came from Harvard. We began from scratch." In particular, he states that he never looked at any drawings from the USA. Furthermore, during the design and building phases of the MMIF, these pioneers, by their own admission, had only very rare contacts with the Americans. Wiedmer [11] says "Aiken visited BTMC once or twice, but he never talked to our engineers nor gave us anything." Iselin [6] agrees: "The influence of the Americans? In my opinion, there wasn't any, except for one or two visits by the head of Bell USA, Mr. Sosthenes, who made a whirlwind tour of the lab, without looking at or speaking to any of us." He adds [7]: "We saw Mr. Aiken one or two times, for about five minutes, during a four-year period." When asked about their educational background, these two linchpins in the design of the MMIF replied that they are both graduates of the ETH (Eidgenössische Technische Hochschule) in Zurich. Wiedmer [13] adds: "The best professors I remember were P. Scherrer for physics and E. Baumann for what is called electronics today. But I also learned a lot in my first job, at Standard Telephon und Radio AG in Wollishofen-Zürich."

Now let's examine the influences experienced by those who worked on programming the MMIF. The sub-routines for elementary functions and for application programs were completed in Antwerp, without any foreign contributions or influences. In this area, the Belgian pioneers "started from scratch", in the words of Meinguet [2]. In addition, Meinguet [8] writes: "the people who have influenced me most in terms of numerical analysis (...) are Belevitch, Stiefel and Rutishauser." And the direct influences cited by Meinguet for programming techniques are Rutishauser, Speiser and Stiefel: these influences are not directly American, but rather Swiss. However, we can

${ }^{34}$ See for instance Figure 3. 
then ask how these three Swiss engineers acquired their expertise. Meinguet [10] shines some light on this subject:

"During their stay in the USA (beginning in October 1948), Professor Stiefel (until March 1949) and his assistants (Rutishauser and Speiser, until late 1949) did serious research about contemporary American achievements and, more broadly, American ideas relating to electronic calculating machines. Like other European forerunners, they then used the acquired knowledge to develop their own ideas. This, I believe, is how things went. This trip took them to New York (Columbia University: Eckert, Courant Institut : Courant and Friedrichs, National Bureau of Standards : Lowan and Salzer), to Washington D.C. (Office of Naval Research: Rees, National Bureau of Standards : SEAC), to Boston (Harvard University: Aiken and the Mark III [machine] in construction) and to Princeton (Institute for Advanced Study: von Neumann and the machine in construction). Stiefel felt validated in his opinion: a relatively simple and slow machine (at moderate cost), but still reliable, would be particularly suitable for the Swiss (science and industry); this led to the design of ERMETH ${ }^{35}$ with its specific characteristics (large memory but with limited speed), whose later construction would also benefit from the experience acquired at ETH on $\mathrm{Z4}^{36}$. In addition, Stiefel and his assistants visited a number of European colleagues, particularly in Germany."

In the end, I thus believe that we can say that Aiken's contribution to the MMIF can be found mostly on two levels: explaining the basic principles of a computer (in particular, to those people who visited Harvard prior to construction of the Belgian prototype) and coaching the leaders of the MMIF construction project. Furthermore, this contribution is restricted essentially to the project's leaders, to the virtual exclusion of the engineers who designed the Machine and the mathematicians who programmed it. Finally, both in terms of the physical architecture and its programming, the American influence on the Belgian project was merely indirect, whereas the direct influence was provided by the ETH in Zurich.

Acknowledgements. I would like to warmly thank the twelve people who provided eyewitness accounts of the MMIF for their support and assistance: they are truly the co-authors of this work. I would also like to recognise the FNRS, which allowed me to use its archives and also made my task much easier by providing a great number of photocopies. I also thank Dr. Sandra Mols, in particular for her contribution to information gathering and for managing the oral interviews, and Professor Robert Halleux, for his advice and support.

${ }^{35}$ Elektronische Rechenmaschine der ETH.

${ }^{36}$ The computer Z4 - based on electromechanical technology - was completed in 1944 by the then almost unknown scientist Konrad Zuse. The machine was fortunately kept safe from Allied bombing over Germany and then leased by ETH, where it served from 1950 to 1954. Z4's long lasting life continued until 1960 at the French Institute of Aerodynamics. 


\section{References}

\section{Sources}

\section{a) "Histoire informatique belge",37 Archival Fund (HIBAF) (Unamur, Namur)}

\section{Unpublished Archives}

- Oral Archives

1. Fosseprez, C.: Telephone communication on May 21, 2008

2. Meinguet, J.: Interview on November 23, 2007

3. Meinguet, J.: Telephone communication on October 2, 2008

4. Meinguet, J.: Interview on November 14, 2008

5. Rouche, N.: Interview on December 3, 2007

6. Iselin, F.: E-mail dated July 12, 2009

7. Iselin, F.: E-mail dated October 10, 2009

8. Meinguet, J.: Letter dated March 11, 2002

9. Meinguet, J.: Letter dated June 24, 2002

10. Meinguet, J.: E-mail dated November 13, 2009

11. Wiedmer, F.: E-mail dated October 12, 2009

12. Wiedmer, F.: E-mail dated November 26, 2009

13. Wiedmer, F.: E-mail dated December 11, 2009

\section{- Documents Pertaining to the Functioning and Programming of the MMIF}

14. CECE: Document no. 1, Manuel de programmation pour la machine mathématique IRSIAFNRS, VI + 157 p. (1957)

15. CECE: Progress Report no. 1, 12 p. (June 1957)

16. CECE: Document no. 2 - Pseudocode Manual for the IRSIA-FNRS Computer, IV $+62 \mathrm{p}$. (1958)

17. CECE: Liste des problèmes traités par le CECE, 5 p. (undated)

\section{Limited-Edition Documents}

18. Bell: Bell Telephone Manufacturing Company 1882-1982. Service Presse et Information Bell Anvers (1982)

19. Linsman, M., Pouliart, W.: La Machine mathématique IRSIA - FNRS, 47 p. Département technique de la Bell Telephone Manufacturing Company, Antwerp (February 1955)

\section{b) FNRS Archival Fund (Brussels)}

20. Aiken, H.: Typewritten letter sent to L. Henry, 1 p. (January 17, 1951)

21. Aiken, H.: Typewritten letter sent to L. Henry, 5 p. (May 14, 1952)

22. Aiken, H., van Wijngaarden, A.: Typewritten letter sent to L. Henry, 2 p. (July 10, 1957)

${ }^{37}$ History of Computing in Belgium. 
23. FNRS 1951: Minutes des réunions des 16 et 17 janvier 1951 à l'IRSIA. D 1/4 - 390/447, 4 p. $(1951)$

24. FNRS 1954: Memorandum. D 1/4 - 7473/447, 1 p. (December 13, 1954)

25. Henry, L.: Présentation et démonstration de la machine à calculer IRSIA-FNRS, Speech given by Mr. Henry, IRSIA Director, 4 p. (1955)

26. Henry, L., Willems, J., Van Dyck, L., Manneback, C.: Convention, 4 p. +2 p. of appendices (January 24, 1951)

27. Manneback, C., Brillouin, L.: Les machines mathématiques aux États-Unis, Rapport au Fonds national de la recherche scientifique (Restricted distribution clause cited on a sticker attached to the report), 35 p. (1947)

\section{c) Printed and Published Sources}

28. Belevitch, V., Storrer, F.: Le calcul numérique des fonctions élémentaires dans la machine mathématique I.R.S.I.A.-F.N.R.S. Bull. Acad. Roy. Belg. XLII, 543-578 (1956)

29. Linsman, M., Pouliart, W.: La Machine mathématique IRSIA - FNRS en construction à la Bell Téléphone Mfg $\mathrm{C}^{\circ}$. Industrie 8, 505-509 (1953)

\section{Secondary Literature}

30. Biot, M.A.: Charles Manneback. In: Académie royale de Belgique, Classe des Sciences (ed.) Florilège des Sciences en Belgique II, pp. 369-377 (1980)

31. Courtois, P.-J.: Notice Biographique de Vitold Belevitch. In: Académie royale des sciences, des lettres et des beaux-arts de Belgique (ed.) Nouvelle Biographie Nationale, vol. X, pp. 35-42 (2010)

32. Courtois, P.-J.: The Belgian Electronic Mathematical Machine (1951-1962): An Account. In: Jones, C.B., Lloyd, J.L. (eds.) Dependable and Historic Computing. LNCS, vol. 6875, pp. 225-237. Springer, Heidelberg (2011)

33. d'Udekem-Gevers, M.: La Machine mathématique IRSIA-FNRS (1946-1962). Académie royale de Belgique, Classe des Sciences, 224 p. (2011)

34. Fosséprez, C.: Les fondements de l'Informatique et des Télécommunications. Notes de cours à l'Université des Aînés (UDA), Louvain-La-Neuve, Belgium (2002)

35. Loeckx, J.: Computer design and software development in Belgium before 1970: a personal retrospect (Text written in March 2007, to be published in 2014) 